\title{
ATIVISMO MÍDIATICO CIRCUNSTANCIAL - UMA ANÁLISE DA RELAÇÃO ENTRE REPRESENTAÇÕES MÍIIÁTIICAS E POLÍTICAS
}

\author{
The circumstantial media activist - an analysis of the relation between media \\ and political representation
}

\begin{abstract}
Activismo mediático circunstancial: un análisis de la relación entre medios y representación política
\end{abstract}

\author{
Paola Madrid Sartoretto \\ Universidade de Estocolmo \\ paola.sartoretto@lai.su.se
}

\section{Resumo}

Mídia alternativa radical (Downing, 2000) é um tipo de produção midiática comum entre movimentos sociais cujos membros não veem suas causas representadas na mídia dominante. Esse é o caso do Movimento Sem-Terra (MST), que desde 1984 tem criado meios de comunicação próprios e produzido conteúdo para plataformas variadas, tornando-se mais tarde ativo na área da democratização da comunicação. Baseado em trabalho de campo realizado em 2013 e 2014, esse artigo propõe uma perspectiva de direito à comunicação que aborde a configuração estrutural do setor de comunicação e não apenas a provisão de tecnologias e habilidades de produção. $O$ estudo demonstra que ação coletiva e promoção de mudanças estruturais ainda são relevantes, aliadas às novas tecnologias de comunicação.

Palavras-chave: Direito à comunicação. Representação. Participação.

\begin{abstract}
Alternative or radical media (Downing, 2000) are kinds of media production common among social movements whose members do not see their causes represented in mainstream media. This is the case of the Brazilian Landless Workers Movement (MST), which since 1984 has created media outlets and produced content for different platforms, becoming later active in the area of media and communication rights in Brazil. Based on fieldwork carried out in 2013 and 2014 this article proposes a perspective to communication rights is attentive to the structural configuration of media landscape and not only to the provision of technology and production skills. This study shows that collective action and promotion of structural change are still relevant alongside new technologies.
\end{abstract}

Keywords: Communication rights. Representation. Participation. 


\section{Resumen}

Los medios alternativos o radicales (Downing, 2000) son tipos de producción mediática comunes entre los movimientos sociales cuyos miembros consideran que sus causas no se encuentran representadas en los medios masivos. Este es el caso del Movimiento de los Trabajadores Rurales Sin Tierra (MST por su sigla en portugués) en Brasil, que desde 1984 ha creado medios propios y producido contenido para diferentes plataformas y eventualmente se tornó activo en el ámbito del derecho a la comunicación. En base a trabajo de campo desarrollado en 2013 y 2014, este artículo propone un enfoque del derecho a la comunicación atento a la configuración estructural del ámbito mediático, y no sólo a la provisión de tecnologías y capacidad de producción. El estudio muestra que la acción colectiva y la promoción del cambio a nivel estructural siguen teniendo relevancia junto con las nuevas tecnologías.

Palabras clave: Derecho a la comunicación. representación, participación

\section{INTRODUÇÃO}

Mídias alternativas e produção de noticias contra-hegemônicas existem desde o século XIX (ATTON e HAMILTON, 2008, p.16-17), mas o termo ativismo midiático, em inglês, (media activism) é usado especificamente para categorizar iniciativas contemporâneas (MILAN, 2013). A partir da segunda metade do século XX a produção midiática fora dos veículos de comunicação institucionalizados e grandes corporações se intensificou em várias regiões (veja por exemplo ATTON, 2002). Essas publicações incluíam fanzines, mídia ativista, rádios alternativas e produção audiovisual. Existem, portanto, diferentes (e às vezes conflituosas) noções de mídia alternativa, que também pode ser chamada "mídia radical" (DOWNING, 2000), mas o denominador comum entre as definições é o comprometimento dos meios de comunicação alternativos com a produção coletiva, participação democrática e com os direitos de minorias e classes subalternas à auto-expressão (GUMÚCIO-DAGRON 2004; RODRIGUEZ, 2003). Veículos alternativos também respondem e materializam demandas de diferentes grupos por representação.

Consequentemente, a produção midiática de ativistas e movimentos sociais é por definição alternativa no sentido de que é uma forma de auto-representação, geralmente produzida coletivamente e sem fins comerciais.

Neste artigo, mídia ativista é abordada como uma categoria de mídia alternativa buscando discutir a relação entre mobilização social e ativismo midiático. Mas o que diferencia ativismo midiático de outras formas de ativismo? Uma resposta simples seria dizer que ativismo midiático tem seu foco em demandas específicas do campo dos meios de 
comunicação, com o objetivo de resgatar ou obter o controle desses como canais para comunicação, circulação de conteúdo e representação. Milan (2013) cita ativismo digital em rede, rádio e televisão comunitários e ativismo tecnológico como formas de ativismo midiático. Ativismo midiático pode, às vezes, significar o simples ato de utilizar diferentes mídias para chamar atenção do público para problemas sociais que afetam um determinado grupo. Pode também incluir a criação de canais e veículos alternativos aos tradicionais (ZHAO, 2003) e, em um nível estrutural, pode incluir também ações que objetivam alterar a estrutura do setor de comunicações em uma determinada região.

O ativismo midiático surge da percepção de que veículos de comunicação dominantes ou hegemônicos não representam a pluralidade de grupos e interesses em uma determinada sociedade, e, consequentemente, não podem ser considerados arenas nas quais problemas e questões que afetam minorias e grupos marginais possam ser discutidas. Ativismo midiático também pode agir contra a vigilância digital, promovendo o acesso a espaços seguros para discussão e troca de informações (MILAN, 2013). Tais questões tem sido discutidas em fóruns internacionais desde os anos oitenta, culminando com a publicação pela UNESCO do relatório One World, Many Voices, e continuando mais tarde com os World Summits on the Information Society (WSIS) em 2003 e 2005. O primeiro relatório já chama atenção para o fato de que muito se fazia para garantir o direito de receber informação em detrimento do direito de produzir e circular mensagens. Esse tipo de desequilíbrio afeta especialmente populações rurais e indígenas ao redor do mundo, muitas das quais vivem em países onde os meios de comunicação são essencialmente comerciais com sua propriedade concentrada entre poucas corporações. Esse é o caso do Brasil, onde trinta famílias dominam os mercados nacionais e regionais no setor de mídia. Em consequência disso, populações rurais e indígenas tem acesso restrito aos meios e tecnologias de comunicação e não tem oportunidade de discutir na mídia questões que lhes são relevantes. Nesse contexto, o objetivo desse artigo é salientar o papel crucial dos meios de comunicação midiática em processos de mobilização social, representação (de acordo com FRASER, 2009) e participação política.

Ao mesmo tempo, argumenta-se que, mesmo com o surgimento das redes e plataformas de comunicação digital, os aspectos político-econômicos ainda estruturam a distribuição de poder simbólico através dos meios de comunicação. Em concordância com o argumento de Fuchs e Sandoval (2009, p.141) de que não devemos ser exageradamente otimistas quanto aos "efeitos democráticos" das mídias alternativas, pretende-se oferecer 
evidência empírica sobre a relevância dos aspectos politico-econômicos e estruturais para a democratização da comunicação.

Recentemente, ativismo midiático se tornou uma área específica de ativismo social, haja visto que o direito à comunicação se torna uma demanda no mesmo nível de questões ambientais, de gênero e direitos humanos (PERUZZO, 2014).

Para que se possam abordar as questões identificadas acima, discute-se o caso do Movimento Sem-Terra (MST), um dos maiores movimentos sociais da América Latina, com mais de trinta anos de atividade e 1,5 milhões de membros. O MST foi fundado como uma organização de classe com o objetivo de promover a redistribuição de terras no Brasil através da reforma agrária. A principal forma de ação do movimento é a ocupação de terras que não cumprem sua função social de acordo com a Constituição brasileira, podendo assim serem expropriadas, com subsequente formação de acampamentos que podem se tornar assentamento caso os ocupantes recebam a propriedade da terra. Desde a sua fundação em 1984, o MST tem envidado esforços na criação de veículos de comunicação, dos quais o Jornal Sem-Terra e as rádios em assentamento são exemplos. Entretanto, militantes do movimento perceberam logo no estágio inicial que precisavam agir contra a concentração dos meios de comunicação e as relações insidiosas entre proprietários de terra, políticos e empresas de agronegócio. Desde então o movimento se tornou um ator nas áreas de democratização da comunicação e do direito à comunicação em paralelo à sua atuação na promoção da reforma agrária, tornando-se membro no Fórum Nacional para a Democratização da Comunicação (FNDC) e promovendo ativamente a democratização da comunicação e o direito à comunicação em paralelo ao trabalho pela reforma agrária.

A análise do envolvimento do MST com o ativismo midiático foi desenvolvida através de entrevistas e observações durante trabalho de campo realizado em 2013 e 2014 . Um total de vinte e duas entrevistas e diários de campo referentes a visitas a rádios de assentamento, assessorias de imprensa, uma escola e participação no congresso nacional do MST em 2014 são usados para discutir questões relacionadas à relevância e ao papel dos meios de comunicação para movimentos sociais.

Usando o caso do MST, argumenta-se que o direito à comunicação (DEANE, 2007; PERUZZO, 2007) é fundamental para organizações contra-hegemônicas. Essas organizações só serão representadas na concepção de Fraser (2009) quando tiverem o direito à comunicação garantido. A análise também questiona a ideia de que o direito de comunicação é obtido através da provisão de tecnologias que viabilizam e facilitam a comunicação. Ao 
contrário, as entrevistas apontam para uma relação muito mais complexa entre mídia, comunicação e representação no discurso público.

Através da análise do trabalho do MST como ativista midiático em paralelo à sua principal causa, podem-se adicionar novos ângulos à discussão das relações entre mídia e participação política coletiva. Como ator político estabelecido no Brasil e América Latina, a experiência do MST pode apontar novas direções para a avaliação das oportunidades e desafios que minorias e grupos marginais enfrentam em garantir sua participação política.

O artigo é dividido em quatro seções e conclusão. A primeira seção apresenta um breve panorama da pesquisa e teorias sobre ativismo e ativismo midiático, problematizando o viés tecnologista que permeia análises recentes de ativismo e protesto. A seção seguinte apresenta os métodos utilizados na pesquisa e materiais de análise. As duas últimas seções analisam os resultados a partir de duas perspectivas - discute-se o processo a partir do qual o MST se tornou um ativista midiático circunstancial e se propõe uma concepção de participação na mídia e representação para além do determinismo tecnológico.

\section{ATIVISMO MIDIÁTICO, REPRESENTAÇÃo E PARTICIPAÇÃo}

Organizações de protesto e ativistas perceberam há tempo a importância dos meios de comunicação para atingir seus objetivos e para levar suas causas ao discurso público (GITLIN, 1980; HALLORAN, ELLIOT, E MURDOCK, 1970; RODRIGUEZ，2001; WOLFSFELD, 2004). A grosso modo, práticas midiáticas utilizadas por organizações ativistas podem ser divididas em duas áreas principais: construção de canais próprios que servem para a comunicação entre ativistas e como uma alternativa às instituições hegemônicas de mídia, e desenvolvimento de relações com a mídia hegemônica com o objetivo de comunicar suas causas à sociedade em geral. Com o desenvolvimento e disseminação de novas tecnologias de comunicação que facilitam auto-publicação e circulação de conteúdo, a construção de novas arenas de comunicação ganhou um espaço proeminente também na pesquisa acadêmica ${ }^{1}$. Ademais, com os problemas que emergem a partir do desenvolvimento tecnológico e da disseminação das mídias digitais (vigilância, acesso a tecnologias que se tornam cada vez mais necessárias, censura) direitos ligados à comunicação se tornaram uma área de ativismo social.

${ }^{1}$ Veja por exemplo Rodríguez, 2011; Bennett and Segerberg, 2012

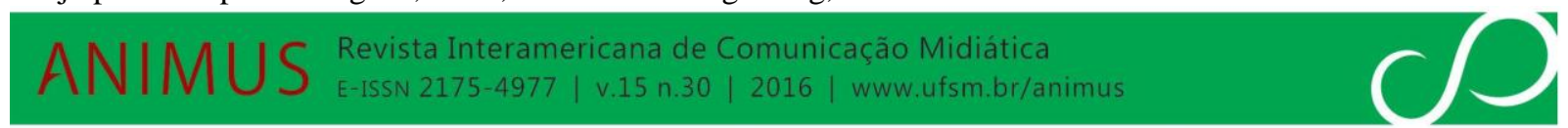


Pode-se então argumentar que a comunicação é um campo de luta social (MILAN, 2013), o que significa que a assimetria de poder e recursos força certos grupos a se valerem de atividades organizadas para assim poderem modificar a distribuição de recursos nesse campo. Mas, se comunicação é um campo de luta, qual seria exatamente o objeto dessa luta? Podemos começar a responder essa questão analisando quais os recursos e que tipo de poder são tão assimetricamente distribuídos ao ponto de ações organizadas serem necessárias para mudar a estrutura de sua distribuição. Uma resposta curta a essa pergunta é que o poder de comunicar é o objeto das lutas travadas pelo ativismo midiático.

Castells (2009) sugere que o poder de comunicar é um elemento decisivo no processo de mudança social, pois é crucial para iniciar outros processos, como, por exemplo, vigilância e censura. Consequentemente, aqueles que detêm o poder de comunicar têm a possibilidade de dominar outros setores na sociedade. Desse modo, Castells (2009) vê as novas tecnologias de comunicação digital como potenciais instrumentos para mudança social porque essas novas tecnologias são mais acessíveis àqueles que não possuem os recursos materiais para poder exercer o poder de comunicação. Por outro lado, Couldry (2012) identifica grandes incertezas na maneira como Castells analisa o poder das redes (network power). O autor argumenta que o poder é exercido socialmente, para além da materialidade das tecnologias, mesmo quando se materializa nas práticas de usar, produzir e consumir mídia. Tal proposição redireciona o foco da análise da descrição dos usos da tecnologia para as práticas sociais que cercam a tecnologia, objetivando construir teorias ético-normativas de comunicação. Ela vai de encontro à visão de Fraser (2009) sobre justiça internacional, que segundo a autora compreende reconhecimento de direitos, diferenças e desigualdades, redistribuição de recursos, e representação política e simbólica.

Fraser (2009, p.6) explica que representação diz respeito a situações em que alguns considerados membros de uma dada sociedade - não podem participar em igual condições das interações sociais. Embora a autora não discuta a mídia ou seu papel nesse processo, o campo da comunicação nos ensina que representação política e simbólica se materializa nas mídias de diferentes maneiras, se aceitamos que as interações sociais ocorrem cada vez mais através de meios de comunicação. E, enquanto a mídia constitui, junto a outras instituições, arenas onde a representação se materializa, é necessário - como propõe Couldry - discutir uma ética da mídia.

Partindo da conceitualização de Fraser (2009), é possível dizer que representação (de grupos, causas ou problemas sociais) é peça-chave em grande parte das mobilizações sociais 
atuais. Consequentemente, ativistas usam diferentes mídias de diversas maneiras para chamar a atenção do público para suas causas, diretamente ou através de veículos de comunicação institucionalizados (GABER e WILSON, 2005; de JONG, 2005; DeLUGA, SUN, e PEEPLES, 2011; GAVIN e MARSHAL, 2011). Nas duas últimas décadas, enquanto as mídias e tecnologias de comunicação tem se tornado indispensáveis em vários aspectos da vida diária, o ativismo midiático tem dirigido seu foco à provisão de tecnologias para aqueles que não possuem acesso e ao combate à vigilância digital exercida por governos autoritários sobre seus cidadãos.

Um aspecto que diferencia o ativismo midiático de outras áreas de ativismo é que, enquanto ativistas e movimentos sociais usam e se relacionam com meios de comunicação enquanto mediadores, o ativismo midiático tem como objetivo transformar a estrutura ou fluxo de comunicação. O Fórum Nacional pela Democratização da Comunicação (FNDC) é um exemplo de organização que atua para transformar a estrutura do setor de comunicação midiática no Brasil. O FNDC é formado por organizações da sociedade civil que reivindicam uma série de demandas incluídas na causa de democratização da comunicação como, por exemplo, a neutralidade de rede, proibir que políticos adquiram veículos de comunicação, e mudanças na regulamentação das rádios comunitárias.

Outro aspecto do ativismo midiático é o seu etos contra-hegemônico que, usando a terminologia gramsciana (1971), significa que as ações são direcionadas no sentido de fazer o contraponto à mídia hegemônica e aos grupos hegemônicos da sociedade. No caso analisado nesse artigo, ambos a mídia hegemônica e os grupos hegemônicos se interseccionam porque políticos e elites (locais, regionais e nacionais) são proprietários de empresas de comunicação. Tal estrutura garante a esses grupos a primazia na interpretação e enquadramento de acontecimentos e causas. Para o MST isso significa três tipos diferentes de obstáculos para atingir debate público: os veículos de comunicação produzidos pelo movimento precisam competir por audiência com veículos hegemônicos, enquanto grupo insurgente o movimento é preterido como fonte de noticias e informações, o movimento é antagonista aos grupos que controlam as grandes corporações midiáticas no Brasil.

Assim, além da luta no plano simbólico, o desenvolvimento de tecnologias e a incidência das mídias em todos os setores da vida moderna - fenômeno descrito pelo conceito de midiatização - fizeram com que as mídias em sua forma material também se tornassem lugares de luta. Até um período recente o que estava em jogo era o acesso a informações relevantes e o direito de participar de discussões através da mídia (CARPENTIER, 2007) 
à representação enquanto minoria nos canais da mídia hegemônica. Entretanto, como tecnologias da comunicação se tornaram essenciais para várias outras atividades humanas (acesso aos órgãos do estado, bancos, educação e sistema de saúde) e são distribuídas de forma desigual entre classes sociais e áreas geográficas, o acesso à tecnologia também se torna um locus de luta social.

Em certos casos, que serão explorados nas seções seguintes, a escassez material e a representação simbólica equivocada estão interconectadas. Tal relação faz emergir questões relacionadas ao acesso e uso de tecnologias para participação política. Ao discutir essas questões, Peruzzo (2014, p.180) considera a comunicação um direito humano que deve ser garantido tanto a indivíduos quanto a comunidades e coletivos, enfatizando a importância da comunicação grupal que estende a cidadania. A autora entende a comunicação comunitária não apenas como uma forma de auto-representação como também uma maneira de consolidar a representação política, em concordância com a visão de Fraser.

Torna-se claro então que ambas - a prática e a teoria - lidam com dois níveis de ativismo midiático - o nível micro do grupo ou comunidade que precisa ter acesso ao direito à comunicação para que possam receber informações relevantes e serem ouvidos, e o nível macro da representação simbólica e política desses grupos em debates nas arenas nacionais e transnacionais que têm lugar na mídia. Considerando esses dois níveis, as análises tendem a se focar apenas no primeiro, por razões compreensíveis. Do ponto de vista empírico é muito mais fácil analisar o nível micro e as relações entre indivíduos e o grupo ou comunidade a que eles pertencem. São necessários, no entanto, maiores esforços empíricos para se estabelecer e discutir relações no nível macro, entre grupos e comunidades e as macroestruturas das quais fazem parte. Mesmo que a intersecção entre ativismo político, mídia, e participação social tenha sido extensivamente pesquisada, essas análises têm, em grande parte, uma perspectiva endógena, isto é, investigam relações sociais internas aos grupos analisados e o uso que tais grupos fazem dos meios de comunicação como um fim em si mesmo. Nesse contexto, partindo da experiência do MST, discute-se o ativismo midiático sob uma perspectiva exógena, isto é, em relação a outros setores da sociedade. De acordo Carpentier (2009) essa perspectiva é atenta à interrelação entre veículos de comunicação alternativos e hegemônicos ao analisar a participação social, buscando aprofundar a análise através do estabelecimento de conexões analíticas entre participação e representação.

Para poder explorar essas conexões, esse estudo faz uma análise dos mecanismos por trás do processo através do qual um movimento social é compelido a utilizar o ativismo 
midiático. O objetivo é explorar e chegar a um entendimento mais profundo sobre a centralidade da comunicação para a participação social democrática, representação e promoção da diversidade nos meios de comunicação.

\section{MÉTODO E MATERIAIS}

A análise apresentada se baseia num corpus de 22 entrevistas com militantes do setor de comunicação do MST (comunicadores de rádio, assessores de imprensa nos níveis nacional e regional e educomunicadores) e observações de atividades nas assessorias de imprensa do MST em São Paulo e Brasília, em uma rádio rural localizada num assentamento no interior do estado de São Paulo, uma escola do MST no Rio Grande do Sul, e durante o sexto congresso nacional do movimento realizado em Brasília em fevereiro de 2014. As entrevistas têm duração de 36 a 120 minutos e foram realizadas durante os trabalhos de campo que ocorreram de julho a setembro de 2013 e fevereiro a março de 2014. Os informantes foram entrevistados em seus locais de trabalho, residências e no Ginásio de Esportes Nilson Nelson, em Brasília, onde aconteceu o congresso nacional do movimento em 2014. Um dos tópicos discutidos nas entrevistas semi-estruturadas foi a participação do MST no Fórum Nacional pela Democratização da Comunicação. Na entrevista, conceitos analíticos relacionados ao projeto de pesquisa em que o estudo se insere foram usados como tema para orientar questões específicas. Tais temas foram traduzidos em questões (veja Quadro 1) durante as entrevistas de acordo com a área de trabalho e experiência dos informantes. Como os informantes exerciam diferentes funções e tarefas e tinham responsabilidades variadas no movimento não seria possível criar um script com questões muito específicas porque essas não seriam relevantes para todos os informantes.

Dois dos conceitos (veja Quadro 1) - potencial contra-hegemônico das práticas midiáticas e potencial dos meios de comunicação contra a dominação - são analisados nesse artigo. Potencial contra-hegemônico das práticas midiáticas explica como militantes do MST vivenciam e refletem sobre suas relações como os meios de comunicação enquanto instituições e como avaliam as possibilidades de desafiar as estruturas hegemônicas através desses meios de comunicação. Potencial dos meios de comunicação contra a dominação engloba as opiniões dos militantes sobre suas experiências na construção de veículos de comunicação próprios do movimento e as possibilidades de que tais veículos possibilitem ao movimento a participação na esfera pública. 


\section{Quadro 1}

\begin{tabular}{|c|c|}
\hline Conceito analítico & Estratégia de entrevista \\
\hline $\begin{array}{l}\text { Potencial contra-hegemônico das } \\
\text { práticas midiáticas }\end{array}$ & $\begin{array}{l}\text { - Discutir expectativas, experiências e avaliações dos } \\
\text { resultados de diferentes processos comunicativos e } \\
\text { práticas midiáticas. } \\
\text { - Questionar como militantes avaliam os processos } \\
\text { comunicativos internos a hegemonia no setor de } \\
\text { comunicação. }\end{array}$ \\
\hline $\begin{array}{lllr}\text { Potencial dos } & \text { meios } & \text { de } \\
\text { comunicação como } & \text { canais para } \\
\text { desafiar a dominação. } & & \end{array}$ & $\begin{array}{l}\text { - Discutir possibilidades e obstáculos associados aos } \\
\text { diferentes canais de comunicação. } \\
\text { - Pedir aos informantes que descrevam suas } \\
\text { experiências com diferentes canais de comunicação. } \\
\text { - Discutir as maneiras como militantes vivenciam sua } \\
\text { participação na esfera pública. }\end{array}$ \\
\hline
\end{tabular}

Quadro 1: relação entre conceitos e perguntas para as entrevistas

As entrevistas foram transcritas e tematizadas de acordo com temas gerados a partir das questões do projeto de pesquisa do qual esse estudo faz parte. Os informantes assinaram um termo de consenso que explicava como as entrevistas seriam usadas. Nesse termo foi dada a oportunidade aos informantes de não permitir o uso de seus nomes. No entanto todas e todos autorizaram o uso de seus nomes em futuras publicações. Os informantes também tiveram acesso às transcrições para eventuais comentários e correções - apenas dois informantes responderam à correspondência com correções de dados factuais.

\section{O NASCIMENTO DO ATIVISTA MídIATICO CIRCUNSTANCIAL - A CENTRALIDADE DA COMUNICAÇÃo PARA A REPRESENTAÇÃo POLÍTICA}

Críticas ao caráter tecnodeterminista e midiacêntrico de análises do ativismo e participação política têm emergido nos últimos anos (MOSCO, 2005; MOROZOV, 2012; 
CURRAN, FENTON, e FREEDMAN, 2012; McCHESNEY, 2013). No campo da comunicação alternativa e democratização da comunicação, o tom inicialmente celebrativo e otimista foi gradativamente substituído por análises mais sóbrias e complexas da relação entre mídia, representação política e simbólica e participação política. Esse estudo traz uma modesta contribuição a essas discussões, propondo o argumento de que os direitos à comunicação são cruciais à participação na esfera pública e podem levar à representação política. Entretanto, o que está em cheque é o entendimento que se tem de direito à comunicação. A partir das entrevistas com militantes do MST é possível afirmar que direto à comunicação vai além do acesso às tecnologias de comunicação, incluindo reformas estruturais no setor de comunicação, que vão possibilitar a grupos excluídos como o MST serem representados em debates públicos através da mídia.

Em primeiro lugar, é preciso observar o papel do MST como ator político e como os militantes do movimento se tornam conscientes de sua posição no cenário simbólico. A importância de estabelecer canais de comunicação e auto-expressão foi reconhecida nos primeiros estágios da formação do movimento. As militantes Itelvina e Solange explicam como o MST iniciou a construção de seus veículos de comunicação como uma forma de autoexpressão (Rodríguez, 2011), mas também com o objetivo de mobilizar a militância do movimento.

[...] a importância do Jornal Sem Terra - da sua concepção na Fazenda Anoni [primeira ocupação do MST], que foi a origem, o nascimento do primeiro jornal impresso que foi a origem do Jornal Sem-terra, é a ideia que ele era uma ferramenta para o movimento, uma ferramenta para formação e informação ao mesmo tempo [...] feito pelos trabalhadores. Mais tarde nós começamos com a ideia de ter um jornalista, editor, editor-chefe, mas sempre jornalistas populares, ligados ao movimento e à toda uma rede que começou nos estados. Eles então eram chamados de zeladores do Jornal Sem-Terra e o zelador era um militante. (Itelvina)

[...] O Jornal Sem Terra foi criado em 1981 como um boletim, foi criado mesmo antes do MST existir oficialmente como movimento, o que aconteceu em 1984. O jornal é um dos nossos principais veículos de comunicação para o debate e discussão com as nossas bases. Então ele é um patrimônio que nós temos como movimento social e ele contribui no sentido de construir uma linha política nacional, uma organização nacional. (Solange)

Essa visão da comunicação mídiatica como uma forma de socialização tem respaldo em correntes sociológicas construtivistas (BERGER e LUCKMAN, 1967) e no interacionismo simbólico. A criação e subsequente institucionalização do jornal do movimento também reflete a visão da comunicação midiática como uma maneira de "tornar algo comum". Nesse caso, a produção coletiva, circulação e consumo do jornal contribuiu para a criação de valores comuns e de uma comunidade de militantes do MST, 
geograficamente espalhados pelo Brasil. O jornal do MST não era apenas um veículo de comunicação no sentido de que transmite mensagens de acordo com o modelo clássico de comunicação (SHANNON e WEAVER, 1949), mas também uma ferramenta para a reprodução de práticas sociais, de acordo com a concepção dos meios de comunicação como aspectos integrantes de realidades sociais (WILLIAMS, 2003; SILVERSTONE, 2007; COULDRY, 2012). O jornal do movimento constituiu uma arena nacional para o compartilhamento de ideias sobre reforma agrária e direitos dos trabalhadores rurais, como também em um veículo para a formação política dentro do movimento. Ele foi e ainda é um veículo crítico (critical media, FUCHS, 2010) e promove a participação na mídia (CARPENTIER, 2012) porque as pautas de cada edição são discutidas entre a base do movimento e as lideranças nacionais e regionais.

Mesmo que o jornal de alcance nacional funcionasse como uma arena para que a liderança nacional compartilhe e discuta linhas políticas amplas, militantes nos acampamentos e assentamentos do movimento sentiam a necessidade de se comunicar localmente e viram no rádio uma possibilidade para fortalecer os assentamentos como comunidades. Em muitos casos, rádios locais colaboravam com o MST concedendo espaço para o movimento em sua programação. Em outros casos os próprios militantes conseguiam implementar estações de rádio rudimentares. Miguél, que trabalha com produção de radio no movimento na década de 1990, conta que, muitas vezes, a militância contava como o apoio de padres católicos que cediam espaço ao MST em suas rádios. Essas rádios são vistas como um instrumento importante de mobilização, mas também como veículos para a circulação de informações relevantes para os moradores de assentamentos e que não fazem parte da cobertura das rádios comerciais.

Nessa mesma época, as atividades do MST como ocupações e protestos começaram a ganhar visibilidade, primeiro na imprensa local e logo depois nacionalmente. Assim que jornais de alcance nacional e canais de televisão começaram a cobrir ocupações e protestos como a marcha nacional para Brasília em 1997, a relação entre o MST e os veículos de imprensa no Brasil começou a se definirii . Está além do escopo desse artigo oferecer uma análise detalhada da cobertura da imprensa sobre o MST e a questão agrária no Brasil, mas é suficiente salientar que os padrões de cobertura e enquadramento se modificaram nos trinta anos de atuação do MST, mas a visão do movimento é de que as grandes corporações de comunicação no Brasil são antagonistas de classe do movimento porque representam os interesses das elites do país. ${ }^{\text {iii }}$. Os trechos abaixo ilustram essa posição. 
...diariamente a imprensa brasileira chega na casa das pessoas como se fosse uma coisa neutra em vez de reconhecer que "não, nós temos um lugar, nós pertencemos à família Marinho, nós somos a rede Globo e nós da rede Globo e da Rede Bandeirantes somos associados da associação brasileira de agronegócio”. Então como é que você olha uma matéria em defesa dos interesses da bancada ruralista das empresas de agronegócio etc sem saber que o Grupo Bandeirantes e a rede Globo, por exemplo, fazem parte da associação brasileira de agronegócio?(Miguel)

a imprensa hegemônica, ou imprensa burguesa ela determina ainda no Brasil muito da opinião pública. Eu digo ainda porque de um período pra cá essa credibilidade vem sendo questionada e isso pelos movimentos de democratização da comunicação, o próprio processo de manipulação da informação que a gente denuncia. (Mayrá)

... há um tempo atrás a gente tinha outra posição em relação à imprensa, a gente se fechava e não falava com a imprensa, o MST raramente falava com a imprensa. A gente tinha um entendimento, na nossa base, de que era inútil falar com a os veículos de imprensa porque eles eram nossos inimigos. Entretanto, ao longo dos anos, nós começamos a perceber que sim, a imprensa pertence à classe dominante, eles são nossos inimigos, mas ao mesmo tempo eles dialogam com a sociedade. Por quê? Porque mais de noventa por cento da população brasileira tem um aparelho de TV e grande parte da classe média assina um jornal. Então nós percebemos que nós precisamos ter um diálogo com a imprensa de alguma forma, e em 2004 nós criamos uma rede de comunicadores do MST. (Solange)

A partir das entrevistas também é possível concluir que a visão dentro do movimento é de que não é possível dar as costas aos grandes veículos de imprensa porque, mesmo sendo controlados pela classe antagonista, eles são importantes mediadores da relação do movimento com a sociedade. Tal modo de ver os veículos de imprensa ilustra o processo de mediação como descrito por Couldry (2007) em que os veículos de comunicação são intermediadores de relações sociais. A crença nesse papel dos veículos de comunicação fica acima da crítica que coloca tais veículos como antagonistas de classe e dá suporte à decisão, tomada pelo movimento, de estabelecer modos de cooperação com certos veículos.

Tal maneira de entender as mídias como instituições (diferente de considerá-las tecnologias) que representam interesses de classe contrários à visão de mundo do MST enquanto ator social é a raiz da ação do movimento como ativista midiático. Dessa forma, a luta do MST para ocupar os meios de comunicação não fica reduzida às representações do movimento, ela abrange também a redistribuição de recursos simbólicos e materiais no Brasil. As demandas do movimento incluem a revisão das concessões públicas para operação de canais de radio e TV, reformulação da lei de radiodifusão para facilitar a operação de rádios comunitárias em áreas rurais e mais rigidez na regulação da comunicação digital para garantir uma rede digital de qualidade e preço adequado para populações rurais. Tais demandas não são diretamente relacionadas com a causa principal do MST como movimento social, mas colocam em evidência a importância do direito à comunicação para que se atinja o direito à 
representação (FRASES, 2009). Como discutido acima, o MST, desde seu surgimento, tem trabalhado no sentido de criar arenas e canais de comunicação dentro do movimento e para além dele - com comunidades locais onde o movimento é ativo e com a sociedade em geral. O que diferencia o movimento de outras organizações de ativistas é a sistematização de suas ações na área da democratização da comunicação em paralelo à sua causa principal. Essa sistematização acontece de várias formas, desde o estabelecimento de programas de estudo e formação em mídia e comunicação até a participação do movimento no FNDC.

As entrevistas com militantes responsáveis por atividades de comunicação evidenciam que o principal problema de comunicação do movimento não é a falta de acesso às tecnologias de comunicação (mesmo que a falta desses recursos seja um problema em certas situações) mas a estrutura desfavorável do setor de comunicações no Brasil. Assim, para que possa ter uma voz e reconhecimento simbólico (FRASER, 2009), o MST foi compelido pelas circunstancias a direcionar seu ativismo para a área de comunicação.

\section{PARTICIPAÇÃo PARA ALÉM DO DETERMINISMO TECNOLÓGICO}

Esse estudo parte de uma concepção de participação como a capacidade de agir socialmente através do engajamento em debates públicos que acontecem nas arenas midiáticas com o objetivo de influenciar agendas políticas. Como coloca Carpentier esse tipo de participação não é suficiente para operar mudanças sociais, mas pode ser um caminho para a representação. A concepção de política que guia o estudo está alinhada a uma visão do campo político que extrapola a política parlamentar institucionalizada (CARPENTIER, 2011, p. 21). No caso do MST, as demandas do movimento (reforma agrária, limites ao poder das empresas de agronegócio) não podem ser implementadas em nível institucional sem que sejam submetidas ao debate público. Os problemas surgem quando o MST, enquanto ator social coletivo representando os afetados pelas políticas (FRASER, 2009), não pode participar de um debate em condições iguais com outros atores.

Como foi discutido na seção anterior, ao longo de sua história o movimento vem tentando ganhar espaço no debate público através da criação de veículos de comunicação próprios (jornal, radio, produção audiovisual). Com a emergência e disseminação da comunicação digital a partir do final da década de 1990, a crença de que a comunicação digital facilitaria a participação de atores sociais como o MST no debate público ganhou força. Através da comunicação digital tais atores seriam capazes de estabelecer redes 
(CASTELLS, 2009) para além de fronteiras geográficas, alcançar a sociedade sem a mediação dos grandes veículos de comunicação.

Entretanto, mesmo que as organizações da sociedade civil venham investindo recursos para ampliar as habilidades em mídia e comunicação (MILAN, 2009b; MILAN, 2009c; LÉON, BURCH, e TAMAYO, 2001) e tentem incorporar novas tecnologias (não apenas a internet como também tecnologias mais antigas quando de seu surgimento) às suas rotinas, a correlação entre acesso à tecnologia e participação em debates mais amplos ainda é difícil de ser estabelecida. Nesse sentido, Carpentier (2011, pp. 27-28) argumenta que há diferenças entre participação, acesso e interação. $\mathrm{O}$ autor observa que acesso e interação são geralmente integrados na definição de participação, resultando em que o fator decisivo à participação, o poder, acaba sendo obscurecido. No caso de grupos marginais e atores minoritários como o MST, essa perspectiva leva a um entendimento de que o acesso às tecnologias e a capacidade de usá-las, o que possibilita a interação, como foi o caso dos jornais e rádios de assentamentos, e mais recentemente o acesso à internet, seria condição suficiente para a participação. Ao contrário, na visão dos militantes do MST, o acesso às tecnologias não é condição suficiente para a sua participação no debate público como ator coletivo:

...o que nós precisamos no Brasil é um conjunto de políticas para a comunicação que sejam realmente públicas, em que os movimentos sociais e todos os grupos sociais possam ter espaço para comunicar e nos também precisamos de um processo de desmonopolização, mas esse processo não pode ser uma simples distribuição: nós vamos ter a rádio comunitária, mas vamos continuar com a rede Globo. Isso não resolve o problema se não terminamos com o monopólio da mídia. Você pode ter uma, duas, três rádios comunitárias, mas você tem também uma um mega conglomerado como a Bandeirantes, Globo, Record, que dominam o mercado. (Solange)

A análise das entrevistas aponta para uma relação mais complexa entre acesso à tecnologia e participação política. Em primeiro lugar, o envolvimento do MST com o ativismo midiático e a incorporação dessas causas revela que a comunicação midiática ainda é uma importante arena de participação política. Em segundo lugar, a análise também demonstra que as mídias enquanto instituições ainda detêm um grande poder de enquadramento da realidade e definição das bases sobre as quais certos assuntos serão discutidos. Como explica um informante, mesmo que o MST tenha conseguido atrair cobertura da imprensa durante seu congresso nacional em fevereiro de 2014, o movimento não teve nenhum controle sobre o enquadramento do evento.

[...] os jornais, eles não reportaram as nossas demandas, ele falaram muito pouco sobre as nossas demandas que são a reforma agrária, porque nós estamos protestando, os trinta anos do MST. Aqueles que falaram sobre isso só nos deram três minutos, cinco segundos, muito pouco tempo. A maior parte da cobertura foi sobre o 
conflito que deu quando a polícia invadiu o nosso protesto porque uns 15 meninos estavam tirando material de um ônibus para uma intervenção teatral. (Solange)

Mesmo tendo organizado uma estrutura de comunicação e relações com a imprensa durante o congresso nacional de 2014, que incluiu um café-da-manhã com jornalistas, duas entrevistas coletivas e um grupo de assessores com a tarefa de acompanhar os jornalistas, o MST conseguiu colocar um número mínimo de suas pautas no noticiário, de acordo com a avaliação do grupo responsável pela comunicação durante o evento. Esse situação não se restringe a esse evento, mas é característica da relação entre o MST e a imprensa hegemônica no Brasil, como as entrevistas desse estudo demonstram.

Alguns autores argumentam (CASTELLS, 2001; JENKINS, 2006, por exemplo) que as mídias digitais poderiam mudar drasticamente a distribuição de poder entre grupos marginais e a mídia hegemônica em razão de seu baixo custo e propriedades que facilitam a colaboração e o trabalho em rede. No caso do MST, alguns avanços foram sentidos em conexão com o advento das mídias digitais. Entretanto, há um reconhecimento de que as condições estruturais do setor de comunicações no Brasil não vão ser modificadas apenas através do uso de tecnologias digitais.

Se nós consideramos nossos canais oficiais, nós estamos avançando um pouco. Por exemplo, através da nossa conta no Twitter nós conseguimos formar a opiniáo pública às vezes, mais do que simplesmente reproduzir o conteúdo do nosso site. Nós tivemos outras experiências, como o blog, um blog da reforma agrária, quando o MST foi submetido a uma comissão parlamentar de inquérito e nós criamos uma rede de comunicadores e uma conta no Twitter. Recentemente, quando a internet $e$ as redes sociais ganham um grande potencial, especialmente entre jovens, nós temos olhado pra esse potencial que a gente tem de colocar a reforma agrária na agenda pública através dessa mídia. Nossa tarefa é tirar o máximo desse potencial para fazer um diálogo com a sociedade, mas nós não podemos esquecer que nossa ação continua nas ruas. (Mayrá)

No Facebook, porque é um espaço onde nós não temos o filtro editorial ou o filtro ideológico, que é o filtro na mídia de massa monopolizada, nós conseguimos expressar a magnitude do nosso protesto, porque nós protestamos. Então eu acho que nesse momento as redes sociais têm um papel muito importante, elas contribuem no sentido de fazer a contra-informação à mídia hegemônica. Entretanto, nós não podemos nos enganar que nós vamos resolver o problema apenas com as redes sociais porque nós também precisamos lugar com a contra-informação contra esses grandes veículos, porque eles são concessões publicas, eles também precisam ouvir o nosso lado, eles precisam parar com essa cobertura que [nos] criminaliza. (Solange)

Esses exemplos mostram que as vantagens trazidas pelo uso das mídias digitais maior alcance de púbico, capacidade de mobilizar redes de apoiadores e simpatizantes rapidamente, melhora na comunicação interna e na circulação de informações entre militantes - não são creditadas aos meios de comunicação, mas às rotinas organizativas que facilitam a apropriação das mídias digitais. Outro aspecto importante, presente nos exemplos acima, é o reconhecimento de que o acesso às tecnologias e a capacidade de produção de conteúdo, embora importantes, não vão ser responsáveis por mudanças a longo prazo. 
Assim, as possibilidades de entrar no debate público através dos canais de comunicação estabelecidos e controlados pelo movimento e simpatizantes são limitadas. Consciente disso, o MST começou a direcionar suas ações para o ativismo midiático. Por volta de 2012 o movimento passou a participar mais ativamente do FNDC, um conjunto de organizações da sociedade civil que promove uma variedade de ações com o objetivo de mudar a estrutura político-econômica do cenário das comunicações no Brasil. Sua principal campanha engloba a operacionalização e aplicação dos termos da Constituição de 1988, que proíbe a formação de oligopólios e monopólios no setor de comunicação ${ }^{\text {iv }}$. A organização também promove controle e regulamentação mais rígida das comunicações digitais para contrabalançar o poder das grandes corporações do setor. Nessa perspectiva, uma renovação na lei de radiodifusão que facilite o estabelecimento de rádios comunitárias em zonas rurais e institua subsídios públicos para aumentar a diversidade dos meios de comunicação e a instituição de um órgão regulador dos meios de comunicação trariam mais mudanças estruturais que beneficiariam mais o MST a longo prazo do que o simples acesso à internet e outras novas tecnologias de comunicação. Isso não diminui a importância dessas tecnologias para atores sociais às margens da esfera pública, mas traz à tona conflitos estruturais de uma realidade sociopolítica da qual as tecnologias de comunicação são um aspecto.

O processo através do qual o MST se engajou no ativismo midiático nos convida a problematizar iniciativas que focam apenas em facilitar uma forma limitada de participação através da comunicação que não traz junto a possibilidade de representação na esfera pública. As entrevistas com militantes do MST mostram que o tipo de auto-expressão e autorepresentacão permitida pela mídia é valorizada pelo movimento, mas também que se reconhecem as limitações de tais iniciativas. Através da análise do caso do MST é possível questionar as limitações políticas do conceito de rede (CASTELLS, 2009) e argumentar por uma análise mais ancorada em fatores políticos do papel dos meios de comunicação para atores sociais marginais.

\section{CONSIDERAÇÕES FINAIS}

Este artigo teve como objetivo discutir as possibilidades e limitações trazidas pelas tecnologias de comunicação digital para a ação de atores sociais marginais através da análise dos processos comunicativos no MST. Através de entrevistas com militantes ativos no setor de comunicação da organização foi possível questionar teorias que veem as mídias digitais 
como agentes de mudanças estruturais no posicionamento de atores sociais marginais. Obviamente essa é a análise de um caso particular e precisa ser continuada com mais estudos que investiguem os papéis dos meios de comunicação para atores sociais em uma macroperspectiva que leve em conta as estruturas sociopolíticas em que esses atores se inserem. Considerando esses resultados, argumenta-se que estudos que investigam as experiências de atores sociais consolidados e autônomos (em vez de intervenções sociais promovidas por organizações internacionais) em democracias emergentes e países em desenvolvimento têm uma importância crucial para contrabalançar o foco recente em ações de ativistas facilitadas pelos veículos de comunicação digital e que ignoram ações continuadas como é o caso do MST e outros grupos militantes. Como resultado, o ativismo individual facilitado pela tecnologia vem ganhando importância como objeto empírico que dá suporte a análises da relação entre tecnologia e participação social. Não obstante, como esse estudo propõe, ação coletiva e promoção de mudanças estruturais no setor de comunicação ainda são relevantes, mesmo numa época em que muitas pessoas já consigam expressar seu descontentamento através das mídias digitais. Se o direito à comunicação e a promoção de mudanças estruturais no sistema político-econômico dos meios de comunicação são suficientemente relevantes para canalizar as ações de um dos maiores movimentos sociais da América Latina, também merecem um lugar proeminente nas agendas de pesquisa.

Estudos recentes têm demonstrado com sucesso como plataformas de comunicação digitais facilitam ações episódicas e performáticas. (TUFECKI e WILSON, 2012; BENNETT e SEGERBERG, 2012). Entretanto, o impacto dessas ações e o tipo de mudança social que elas desencadeiam só pode ser analisado por investigações que levem em conta o nível macro da representação simbólica e política (FRASER, 2009) e não apenas o nível micro da participação. Tomando emprestados os termos usados por Carpentier (2010) um foco muito restrito em participação nos meios de comunicação - aqueles em que a participação é permitida - pode ofuscar a análise da participação através da mídia, que é mais complexa e requer mudanças estruturais.

Uma quantidade considerável de estudos realizados no contexto Europa-América do Norte tem explorado os pontos-de-vista e práticas de protesto em organizações e grupos com base no hemisfério norte onde o acesso à tecnologia e o conhecimento não são barreiras individuais, em comparação com os países em desenvolvimento. Também é necessário considerar que os problemas de representação que afetam países no Sul global requerem um aparato teórico e analítico adequados às condições históricas e estruturais nessas áreas. 
Enquanto grande parte das mobilizações sociais nas áreas mais desenvolvidas é desencadeada pela perda de direitos e recursos materiais, a mobilização social nos países do Sul global - da qual o MST é um exemplo - surge da total supressão de direitos. Essa diferenciação é crucial para que se possa entender como se constroem as práticas midiáticas nesse tipo de organização.

\footnotetext{
${ }^{\text {i }}$ Participação através da mídia, de acordo com Carpentier (2007), é o processo através do qual certos grupos têm suas causas e demandas representadas pela mídia e são ouvidos como fonte. É diferente de participação na mídia, que define a participação direta de uma comunidade ou grupo no gerenciamento e administração de veículos de comunicação.

ii Durante a década de 1990 havia uma maior aceitação às atividades do MST, mas no início deste século os grandes veículos de comunicação tenderam a ignorar o movimento enquanto ator político.

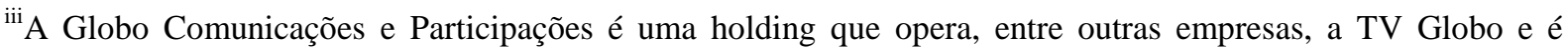
também membro da Associação Brasileira do Agronegócio (ABAG).

${ }^{\text {iv }}$ O Código Brasileiro de Telecomunicações, sancionado em 1962 não estabelece a criação de um órgão regulador, como é o comum em vários países Europeus (Por exemplo o Office of Communications, Ofcom, no Reino Unido.
}

\section{REFERÊNCIAS}

ATTON, C. Alternative Media. London: Sage, 2002.

ATTON, C. e HAMILTON, J.F.Alternative Journalism. London: Sage, 2008.

BENNETT, W. L. e SEGERBERG, A. The logic of connective action: Digital media and the personalization of contentious politics. Information, Communication and Society, v.15, n.5, 2012, p. 739-768.

BERGER, P. e LUCKMAN, T. The Social Construction of Reality - A treatise in the sociology of knowledge. New York: Doubleday, 1967.

CARPENTIER, N. Four Approaches to Alternative Media. In: BAILEY,O. G.; CAMMAERTS, B.; CARPENTIER, N. (Eds.), Understandig Alternative Media. New York: Open University Press, 2007. p. 3-34.

CARPENTIER, N. Participation is not Enough: The Conditions of Possibility of Mediated Participatory Practices. European Journal of Communication, v. 24, n.4, 2009, p. 407-420.

CASTELLS, M. Communication Power. Oxford: Oxford University Press, 2009. 
The Internet Galaxy. London: Oxford University Press, 2001.

COULDRY, N. Media, Society, World: Social Theory and Digital Media Practice. London: Polity, 2012.

.Theorising Media as Practice. In: BRÄUCHNER,B.; POSTILL, J.

(Eds.).Theorising Media and Practice, 35-55. New York: Berghahn Books, 2010. p. 35-55.

CURRAN, J.; FENTON, N.; FREEDMAN, D. Misunderstanding the Internet. London: Routledge, 2012.

DEANE, J. Democratic advance or retreat? Communicative power and current media developments. Global Civil Society, 2007. n. 8.

DE JONG, W. The power and limits of media-based international oppositional politics- a case study: the Brent Spar conflict'. In: DE JONG, W.; SHAW, M.; STAMMERS, N. Global Activism, Global Media. London: Pluto Press, 2005. p. 100-124.

DE LUGA, K.; YE SUN, M.; PEEPLES, J. Wild public screens and image events from Seattle to China: Using social media to broadcast activism beyond the confines of democracy. In: COTTLE, S.; LESTER, L. (Eds.). Transnational Protests and the media. New York: Peter Lang, 2011. p. 143-158.

DOWNING, J.D. 2000. Radical Media - Rebelious Communication and Social Movements. Thousand Oaks: Sage, 2000.

FRASER, N. Scales of Justice - Reimagining Political Space in a Globalizing World. New York: Columbia University Press, 2009.

FUCHS, C. Alternative Media as Critical Media. European Journal of Social Theory, 2010. v. 13. n.2. p. 173-192.

GABER, I.; WILLSON, A.W. Dying for diamonds: The mainstream media and NGOs - a case study of ActionAid. In: DE JONG, W.; SHAW, M.; STAMMERS, N. Global Activism, Global Media. London: Pluto Press, 2005.95-109.

GAVIN, N. T.; Marshall, T. 2011. Climate change and international protest at Copenhagen: reflections on British television and the web. In: COTTLE, S.;

LESTER, L. (Eds.). Transnational Protests and the media. New York: Peter Lang, 2011. p. 197-212.

GITLIN, T. 1980. The whole world is watching: Mass media in the making and unmaking of the new left. Oakland: University of California Press, 1980.

GRAMSCI, A. 1971. Selections from the Prison Notebooks. New York: International Publishers, 1971. 
HALlORAN, J. D.; ELLIOT, P.R.C.; MURDOCK, G. Demonstrations and communication: A case study. London: Penguin books, 1970.

JENKINS, H. Convergence Culture: Where old and new media collide. New York: NYU Press, 2006.

LÉON, O.; BURCH, S.; TAMAYO, E. Movimientos Sociales en la Red. Agencia Latino Americana de Información, 2001.Disponível em: http://alainet.org/publica/msred/msrweb.pdf >. Acesso em: 4 out., 2012

MCCHESNEY, R. W. Digital Disconnect: How capitalism is turning the internet against democracy. New York: The New Press, 2013.

MILAN, S. 2009b. Communication for Development in Practice: A Four-step Path to Implement Community Media Needs in Development Projects. Development in Practice, 2009. v. 19. n. 4 e 5. p. 598-609.

Community Media activists in Transnational Policy Arenas: Strategies and

Lessons Learnt. In: HOWLEY, K., (Ed.). Understanding Community Media. Thousand Oaks: Sage, 2009. p. 308-317.

2013. Social movements and their technologies: wiring social change.

Thousand Oaks: Palgrave Macmillan, 2013.

MOROZOV, E. The Net Delusion - How not to liberate the world. London: Penguin Books, 2012.

MOSCO, V. The digital sublime - myth, power and cyberspace. Cambridge, MA: MIT Press, 2005.

PERUZZO, C. M. Communication in Social Movements: a New Perspective in Human Rights. In: ASKANIUS, T.; OSTERGAARD, L. (Eds.). Reclaiming the Public Sphere: Communication, Power and Social Change. Thousand Oaks:Palgrave Macmillan, 2014. p. $67-83$

- Direito à comunicação comunitária, participação popular e cidadania. Revista Lumina, 2007 , v.1. n.1. p. 1-29.

SHANNON, C. E.; WEAVER, W. 1949. A mathematical theory ofcommunication. Urbana IL: University of Illinois Press, 1949.

RODRÍGUEZ, C. Fissures in the mediascape: An international study of citizens' media. New Jersey: Hampton Press, 2001.

Citizens' media against armed conflict: Disrupting violence in Colombia.

Minneapolis: University of Minnesota Press, 2011.

SILVERSTONE, R. Media and Morality: on the Rise of the Mediapolis. 
Cambridge: Polity Press, 2007.

TUFECKI, Z.; WILSON, C. (2012). Social media and the decision to participate in political protest: Observations from Tahrir Square. Journal of Communication, 2012 v.62. n.2. p. 363-379.

WILLIAMS, R. Television - Technology and cultural form. London e Nova York: Routledge, 2003.

WOlfsfeld, G. Media and the Path to Peace. Cambridge: Cambridge University Press, 2004.

ZHAO, Y. Falun Gong, Indentity, and the Struggle over Meaning Inside and Outside China. In: COULDRY, N.; CURRAN, J. (Eds.). Contesting media power: Alternative media in a networked world. Lanhan: Rowman and Littlefield Publishers, 2003. p. 209-226

Instituto de Estudos Latino Americanos / Universidade de Estocolmo

Esta obra está licenciada sob uma Licença Creative Commons. 